\title{
A web-based platform on COVID-19 to maintain Predicted Diagnostic, Drug and Vaccine candidates
}

Sumeet Patiyal ${ }^{1 *}$, Dilraj Kaur ${ }^{1 *}$, Harpreet Kaur $^{2 *}$, Neelam Sharma ${ }^{1 *}$, Anjali Dhall ${ }^{1}$, Sukriti Sahai $^{3}$, Piyush Agrawal ${ }^{1}$, Lubna Maryam ${ }^{1}$, Chakit Arora ${ }^{1}$, and Gajendra P.S. Raghava ${ }^{1 \#}$

1. Department of Computational Biology, Indraprastha Institute of Information Technology, New Delhi-110020, India.

2. Bioinformatics Centre, CSIR-Institute of Microbial Technology, Sector 39-A, Chandigarh-160036, India.

3. School of Biotechnology, Gautam Buddha University, Greater Noida, India

* Joint first author

\section{Emails of Authors:}

Gajendra P.S. Raghava: raghava@iiitd.ac.in

Sumeet Patiyal: sumeetp@iiitd.ac.in

Harpreet Kaur: harpreet5aug@imtech.res.in ; hks04180@gmail.com

Neelam Sharma: neelams@ iiitd.ac.in

Dilraj Kaur: dilrajk@iiitd.ac.in

Anjali Dhall: anjalid@iiitd.ac.in

Sukriti Sahai: sahaisukriti08@gmail.com

Piyush Agrawal: apiyush74@gmail.com

Lubna Maryam: lucymary20@gmail.com

Chakit Arora: chakita@iiitd.ac.in

\section{\# Correspondence}

Professor, Department of Computational Biology

Indraprastha Institute of Information Technology,

Okhla Industrial Estate, Phase III, New Delhi 110020,

India. Tel.: +91 011 26907444; E-mail address: raghava@iiitd.ac.in 


\section{$1 \quad$ Abstract}

2 A web-based resource CoronaVIR (https://webs.iiitd.edu.in/raghava/coronavir/) has been 3 developed to maintain predicted and existing information on coronavirus SARS-CoV-2. We 4 have integrated multiple modules including "Genomics", "Diagnosis", "Immunotherapy" and 5 "Drug Designing" to understand the holistic view of this pandemic medical disaster. 6 Genomics module provides genomic information of different strains of this virus to 7 understand genomic level alterations. The Diagnosis module provides detailed information on currently-in-use diagnostics tests as well as on five novel universal primers-sets predicted using in silico tools. The Immunotherapy module provides information on epitope-based potential vaccine candidates

(e.g., LQLPQGTTLPKGFYA,

11 VILLNKHIDAYKTFPPTEPKKDKKKK, EITVATSRTLS, GKGQQQQGQTV,

12 SELVIGAVILR) predicted using state-of-the-art software and resources in the field of immune-informatic. These epitopes have potential to activate both adaptive (e.g., B-cell, Tcell) and innate (e.g., vaccine adjuvants) immune systems as well suitable for all strains of SARS-CoV-2. Besides, we have also predicted potential candidates for siRNA-based therapy and RNA based vaccine adjuvants. Drug Designing module maintains information about potential drug targets, tertiary structures and potential drug molecules. These potential drug molecules were identified from FDA approved drugs using the docking-based approach. We also compiled information from the literature and the Internet on potential drugs, repurposing drugs and monoclonal antibodies. To understand host-virus interaction, we identified cellpenetrating peptides in the virus. In this study, state-of-the-art techniques have been used for predicting the potential candidates for diagnostics and therapeutics.

Keywords: COVID-19; SARS-COV-2; 2019-nCoV; Resource; Corona; Vaccine; Drug; Diagnosis; Bioinformatics; Prediction

Introduction:

The year 2019 ended with the outbreak of a new disease called pneumonia of an unknown cause that occurred in China (1). Several independent laboratories identified the causative agent of this enigmatic pneumonia as a novel coronavirus, which has been named as severe acute respiratory syndrome coronavirus 2 (SARS-CoV-2), and the disease caused by this has been named as coronavirus disease-19 (COVID-19) (2-4) The World Health Organization (WHO) has declared this outbreak as pandemic because the virus has spread across the globe 
and infected thousands of people within months of its emergence. As of April 3, 2020, more than 1 million people are reported as infected with COVID-19. With this high rate of increase of this infection, the damage has reached an alarming number of more than 54,000 deaths, with more than 14,000 deaths in Italy alone (5). SARS-CoV-2 belongs to a family of coronaviruses, which are highly diverse, enveloped, positive-sense, single-stranded RNA viruses (6). It shares a $79.5 \%$ sequence identity with SARS-CoV-1 and $96.2 \%$ identity with bat CoV RaTG13 (7). The phylogenetic analysis indicates that SARS-CoV-2 belongs to subgenus Sarbecovirus of the genus Betacoronavirus and is distinct from SARS-CoV-1 (24). SARS-CoV-2 is a new strain of coronavirus which is the seventh member of the family of coronaviruses to infect humans, after MERS-CoV and SARS-CoV-1. It has been shown in recent studies that this new strain uses the same cell receptor, i.e. angiotensin-converting enzyme 2 (ACE2) for the entry into the host cell as used by earlier strains of coronavirus (8). Yushun Wan et al suggested that the single N501T mutation in Spike protein of SARS-CoV2's probably significantly enhanced its binding affinity for ACE2 (9). The exact mechanism of action for SARS-CoV-2 is still needed to be discovered (10).

Due to the pandemic nature of the COVID-19 outbreak and the increase in global incidences, consistent efforts are going on to contain the situation and manage the infected patients. While there has been an exponential rise in the research studies, no effective treatment or vaccine is yet available for COVID-19. However, several clinical trials have been proposed or are undergoing (11). The majority of these trials are being conducted all over the world, for instance, the two largest trials are GDCT0379047 (ChiCTR2000029573) and GDCT0379500 (ChiCTR2000029602) (12). A clinical trial to evaluate the efficacy of the antiviral 'Remdesivir' has also begun in the US by NIH (13). Apart from these, various standard therapies such as antipyretic therapy, oxygen therapy, renal replacement therapy (RRT), and drugs related to SARS such as Oseltamivir, the combination of IFN- $\alpha$ and lopinavir/ritonavir are in current clinical use for managing infected patients (14). It is also crucial to note that the current progress in the coronavirus vaccine research wouldn't have been possible without the endeavor of clinical bioinformaticians working behind closed doors. With the elucidation of the SARS-CoV-2 biological sequence, there have been numerous attempts to understand the virus at the molecular scale, which has led to the development of various in-silico tools and resources notably (15). Various online dashboards were developed by the researchers such as at John Hopkins CSSE, which can be further used to track the COVID-19 cases in real-time and also for other important statistics (16). 
An individual researcher or research group or even a single institute has insufficient resources and knowledge to provide a time-bound solution against a pandemic (e.g., COVID-19). To provide effective solutions against a deadly disease in limited time, one should generate and promote open-source resources. These resources can be used by experimental researchers and clinicians to provide ultimate solutions against any epidemic or pandemic. In this study, we developed a platform that offers computer-aided solutions to manage COVID-19. These resources are generated using state-of-the-art techniques in the field of bioinformatics. These computer-aided solutions include primers for diagnosis, molecules for therapeutic (drugs \& vaccine). In order to provide complete and comprehensive information, we also compile information from the literature and the Internet. To facilitate the scientific community against this deadly disease COVID-19, we provide a web-based platform.

\section{Material and Methods}

\section{General Information}

There is a variety of relevant information regarding SARS-CoV-2 virus and its resulting disease COVID-19. This information is scattered in different forms like literature, webresources, and databases. We performed keyword search on google search engine using different terms relevant to SARS-CoV-2 and COVID-19. We manually evaluate these links obtained from google search to identify authenticated information. Finally, important and authenticated links, videos and documents were compiled and integrated into CoronaVIR.

\section{Genomic and proteomic data collection}

The whole genome and proteome sequences of SARS-CoV-2 were retrieved from the NCBI. We have obtained 53 genome sequences of SARS-CoV-2 strains from NCBI (17). Besides, a total of 10 protein sequences of the Wuhan genome (Accession ID MN908947.3) were extracted till February 2020.

\section{Diagnosis}

93 Firstly, PubMed and Google search engines were mined using keywords like "2019-nCoV 94 Diagnosis", "Diagnostic Primers", "2019-nCoV" and "COVID-19", etc. This information was used to identify 12 diagnostic assays and primers (primer combinations) from four publications; reported till March 1, 2020. Secondly, we downloaded 53 complete genomes (Accession ID with other information like strain and source country given in Table S1 (Supplementary Material) and 40 nucleotide sequences of the 5 genes (N, E, M, ORF1ab, ORF1ab-RdRP) of COVID-19 from the NCBI Virus Resource (18) on March 10, 2020.

100 Thirdly, we designed primers corresponding to whole-genome and specific genes using the 
101 Primer3_core tool $(19,20)$ with default parameters. Notably, we have generated primers for each of the sequences individually in case there are multiple sequences present for any of the genes. Subsequently, we removed duplicate primer pairs for each of the sequences or genes. In addition, we also compiled the diagnostic primers of other strains of coronavirus from the MRPrimerV (21), a public database of primers for viruses Besides, we have also collected and compiled the information regarding the various diagnostic tests for COVID-19 from the literature.

\section{Vaccine Design}

109 To identify potential peptides that could serve as vaccine candidates, we generate all possible

110 9-mer peptides from different proteins of SARS-CoV-2 (Accession No MN908947). A wide

111 range of immune-informatics tools have been used to predict B-cell epitopes, T-cell-epitopes,

112 MHC binders, and vaccine adjuvants.

113 B-cell epitopes: In this study, LBtope (22) has been used to predict B-cell epitopes from the 114 above 9-mer peptides of the different proteins of SARS-CoV-2. LBtope is a highly efficient 115 method that is built and trained on the vast dataset of B-cell epitopes and non-epitopes that 116 were experimentally validated, implemented in numerous studies (23-27). The prediction 117 was made with the default threshold of $60 \%$ cut-off, which was also previously used by 118 Gupta et. al. for designing epitopes for the Zika virus (28).

119 T-cell epitopes: To predict Cytotoxic T lymphocytes (CTL), we used the immune120 informatics tool CTLPred (28). It is a direct method which is based on the primary sequence 121 of the antigens for predicting the CTL epitopes rather than predicting the MHC class I binders. It has implemented machine learning techniques such as artificial neural network $(\mathrm{ANN})$ and support vector machine (SVM). In this work, CTL epitopes were predicted using ANN module of the CTLpred with the default parameters and with the cut-off score of 0.51 .

125 Promiscuous MHC binders: The major histocompatibility complex (MHC) plays a key role 126 in the human immune system. It expresses on the cell surface and binds to the antigenic 127 peptides. Subsequently, it presents the peptide to activate the T-cells. In this study, potential 128 MHC Class I and Class II binders identified using ProPred 1 (28) and ProPred (28), respectively. The prediction was done with the default parameters, i.e., $4 \%$ threshold for

130 ProPred 1 to predict MHC Class I binders and 3\% threshold for ProPred for predicting MHC 131 Class II binders. We identified promiscuous MHC binders that can bind to large number 132 MHC alleles.

133 Experimentally validated epitopes: The Immune Epitope Database (IEDB) (28) is the 134 repository that contains a significant number of experimentally validated epitopes or 
antigenic regions that tend to modulate the immune system. Therefore, with an aim to identify only those epitopes of SARS-CoV-2 that have already been characterized in the past, we have mapped the epitopes predicted in our study with the experimentally proven IEDB epitopes. To further narrow down the search, we have used the different filters i.e., coronavirus as source organisms and coronavirus protein as antigen name to extract the epitopes.

141 Vaccine Adjuvants: We have used VaxinPAD (28) to identify the potential peptide-based vaccine adjuvants. It is used to predict the immuno-modulatory peptides or Antigenpresenting cell epitopes (A-cell epitopes). For determining the potential peptide-based vaccine adjuvants, we have used the SVM based model with the threshold of -0.5 . In addition to peptide-based vaccine adjuvants, we predicted nucleotide-based vaccine adjuvants from genes of 10 proteins (see Table S2, Supplementary Material) of SARS-COV-2 (Accession ID MN908947). In this study, we used the "Batch mode" of VaccineDA with default parameters (28); the length of adjuvants is 30 nucleotides.

\section{RNA therapeutics}

150 With an aim to design siRNA-based therapeutics against the SARS-CoV-2 strain, we generated 19mer oligonucleotide from the corresponding mRNA sequences (Accession ID MN908947), as this length is considered to be sufficient to silence the cognate mRNA target sequence. Previously, many of the prediction methods were developed based on the $19 \mathrm{mer}$ length of siRNA sequence (29-32). To identify which siRNA oligonucleotide could serve as an efficient siRNA against the SARS-CoV-2, we predicted the efficacy of each of oligonucleotides (siRNA) using "DesiRm" software with default parameters (32). Eventually, we have extracted the highly potent siRNAs (having efficacy greater than 0.80 value) and target accessibility of 0.60 .

\section{Drug Designing}

160 In this platform, we integrated the "Drug Designing" module, which elucidates various 161 aspects related to the designing of potential drug candidates for the treatment of COVID-19.

162 Here, mainly four sub-modules have been implemented viz. potential drug target, 3Dstructure, potential drug molecule, and cell-penetrating peptides.

164 Potential Drug targets: This sub-module provides details about potential drug targets that could be used for designing drugs. As this new strain, i.e. SARS-CoV-2 shares high sequence similarity (up to $96 \%$ ) with the previous strains i.e. MERS, SARS, Bat-SARS coronavirus (2,

$16733,34)$, chances of having the same drug targets is higher. Therefore, based on literature searching and previous studies $(2,34)$, we have provided the details of some of the probable 
drug targets such as target name, sequence, locus tag, etc. This complete information was

170 extracted from the complete reference genome sequence of Wuhan Coronavirus (Accession

171 ID: NC_045512.2).

172 Tertiary structure: One of the pre-requisites for designing drugs is the availability of 173 tertiary or three-dimension (3D) structures of drug targets. SARS-CoV-2 encodes a number 174 of proteins that could act as potential drug targets; however, 3D structures of only selective 175 proteins such as spike glycoprotein (PDB ID: 6VSB), and nucleocapsid phosphoprotein 176 (PDB ID: 6VYO) are available in the Protein Data Bank (PDB). We predict the 3D structures 177 of the SARS-CoV-2 proteins using Phyre 2.0 server (7). Towards this, protein sequences 178 were extracted for the complete genome of SARS-CoV-2 (NCBI reference NC_045512.2) 179 from NCBI. Phyre 2.0 is a homology-based software for predicting the 3D structure of a 180 protein. Default parameters were used while predicting the structures except for modeling mode which was set to intensive instead of normal. The quality assessment of the predicted structures was performed using PROCHECK $(35,36)$, and QMEAN software (37). These structures can be used for docking studies for designing new inhibitors.

184 Potential Drug Molecule: An extensive search was performed in different databases like Pubmed, DrugBank (38-40) to identify potential drugs. As there is no FDA approved drug specific to COVID-19 till today, we look for the drugs which have already been approved for the viruses similar to SARS-CoV-2 such as SARS, MERS, etc. The logic behind this approach was based on the similarity of the genomic layout, and the cellular and molecular biology of these viruses.

190 In addition, we used the PatchDock server $(41,42)$ for docking the putative drug molecules to their targets. The parameters used for docking were "clustering RMSD" as 4.0 and "complex type" as the protein-small ligand. Modeled protein-drug structures were further analyzed using PyMOL software (43).

194 Cell-Penetrating Peptides: It is important to identify cell-penetrating peptides in SARS-

195 CoV-2 proteins to understand the mechanism of host-virus interaction. Cell-penetrating peptides in viral proteins help virus to enter into the cell of host. In addition, cell-penetrating peptides can be used for drug delivery. In the past, most of the cell-penetrating peptides were discovered from viral proteins, for example widely used TAT peptides discovered from HIV

199 (44, 45). Here, we used CellPPD (46) to predict the cell penetrating peptides in SARS-CoV-

200 2; each peptide has 10 amino acids. Different physicochemical properties such as 201 hydrophobicity, charge, molecular weight, etc. of the peptides were also computed. Based on 202 the SVM scores, we selected the top 10 CPPs from different viral proteins, which could be 
used as vehicles for drug delivery. The higher the SVM score, the more likely the peptide is

204 to be a CPP.

\section{Webserver Implementation}

206 CoronaVIR has been developed using HTML, PHP 5.2.9, and JAVA scripts. A responsive 207 website based on HTML5 has been used to make the website compatible with mobiles and 208 tablets.

\section{Results}

\section{General Information}

211 In the current study, we have developed a comprehensive web-based resource named as 212 "CoronaVIR" for SARS-CoV 2 or COVID-19. As shown in Figure 1, information has been 213 organized into five modules or categories. First, the module provides general information 214 about this virus and disease. Here we collected and compiled vital information from a wide 215 range of resources including literature. In addition, we have used various in-silico techniques 216 to identify potential diagnostic primers, peptide-based vaccine candidates and potential drug 217 molecules. The overall architecture of the resource is shown in Figure 1. Each of the sections 218 described below in detail.

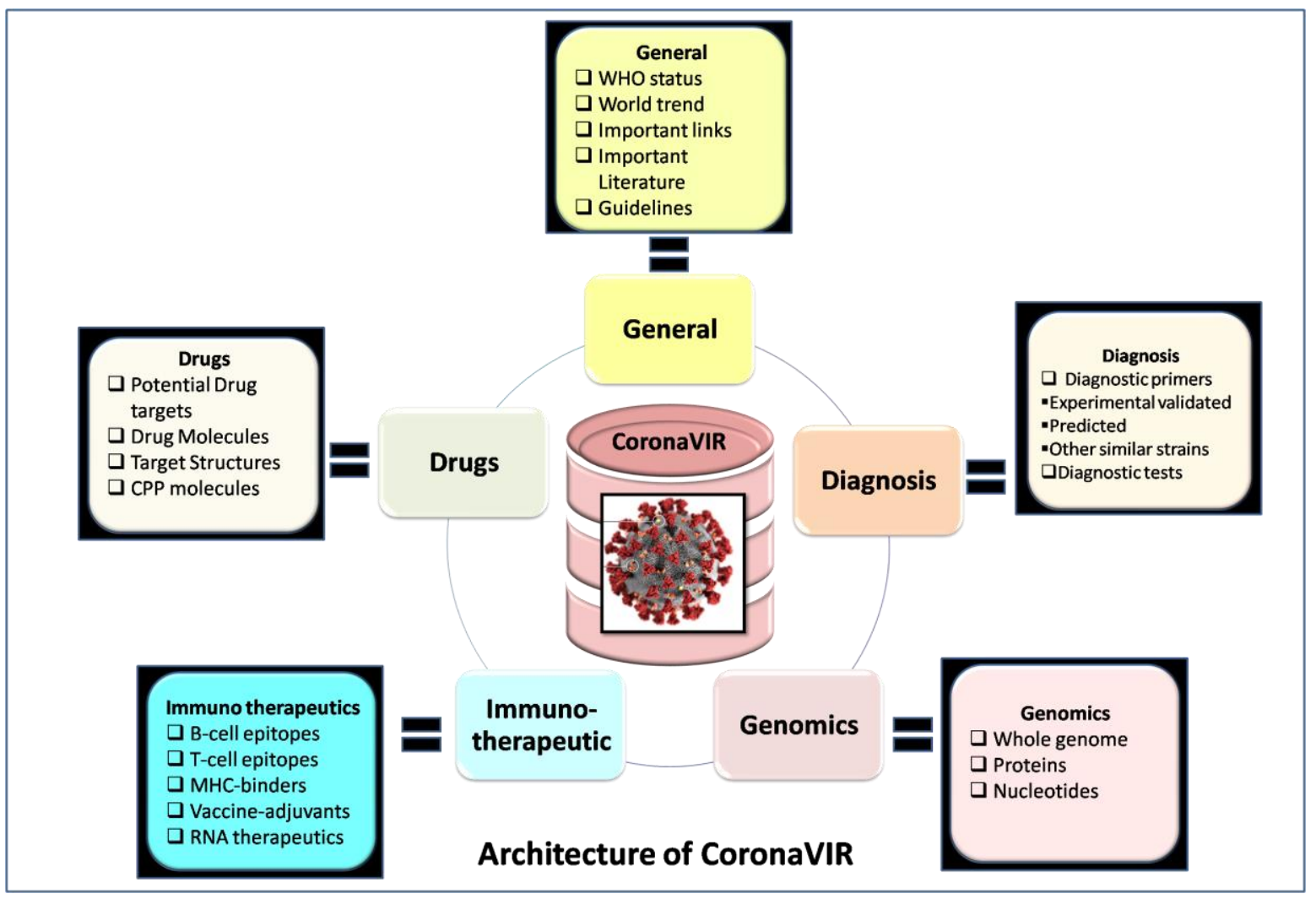




\section{Genomics Module}

223 The 53 genome sequences of SARS-CoV-2 strains were submitted by different groups from various regions worldwide. It includes 25 from China, 19 from the USA, two each from India and Taiwan (Table S1). In order to facilitate community, we have provided comprehensive information on these genomes that includes strain name, size and, Accession ID. In addition, the original source like NCBI resource has been linked. Ten protein sequences were manually checked for the presence and absence of well-reported ORFs, and thereafter categorized. These ten proteins include Orf1ab polyprotein, Orf3a protein, Envelope protein (E), Orf6 protein, Orf7a protein, Orf8a protein, Orf10 protein, spike protein. We have also provided the important links or URLs of NCBI virus genomic resources on the webserver to obtain the latest and updated information regarding genomes.

\section{Diagnosis Module}

Diagnostic Primers: This section provides information about 12 experimentally validated primer pairs collected from the literature. In addition, this section also contains information about 65 unique predicted primers pairs. Following is distribution of these predicted primers; i) five pairs for complete genome, ii) 20 for N-gene \& ORF1ab-RdRP, iii) 10 for ORF1ab and iv) five each for M-gene and E-gene of COVID-19. We named five pairs of primers, which designated from the complete genome as "Universal primers" as they are found to be common among all the 53 different genome sequences, shown in Table 1. In the case of experimentally validated primers, we have provided the gene symbol of the gene against which primers designated, sequences, Tm, and GC content (\%) of forward (Fwd) primers, reverse (Rev) primers and probes (oligo). Experimental assay conditions like Tm,

244 Concentration, etc. are also provided along with the reference study, specific comments regarding their experimental condition or result inference, from the respective study. In case of predicted primers, we have provided information like nucleotide sequences, Tm, and GC content $(\%)$ of the forward (Fwd) primers, reverse (Rev) primers and probes (oligo). Besides, we have also provided information like the ID and country of source sequence, with gene symbols. Further, we have also compiled information (e.g., sequences, TM, GC contents, quality score) for 296 primer pairs for other strains of the coronavirus, obtained from the "MRPrimerV". The detailed information related to all primer sets can be found on the "Diagnostic Primers" sub-module under the "Diagnosis" module on the webserver (https://webs.iiitd.edu.in/raghava/coronavir/prim.php).

254 Diagnostic Tests: This section provides the detailed information of all the possible diagnostic tests which can be carried out for the diagnosis of COVID-19. Besides, this 
module provides guidelines for its collection and storage and the procedure to perform diagnosis via RT-PCR assay, which is the most common diagnostic test used under the current scenario. All the specified information is collected from the recent literature. To facilitate the users, we have also provided the detailed documentation on this on the webserver (https://webs.iiitd.edu.in/raghava/coronavir/diag1.php).

Table 1: Potential candidates for Universal Diagnostic primers sets for COVID-19 (predicted using Primer3_core), which are common among 53 different Genome sequences (obtained from NCBI Virus Resource).

\begin{tabular}{|c|c|c|c|c|c|c|c|c|c|}
\hline Fwd seq & Rev seq & Oligo & $\begin{array}{l}\text { Fwd } \\
\text { Tm }\end{array}$ & $\begin{array}{l}\text { Rev } \\
\operatorname{Tm}\end{array}$ & $\begin{array}{l}\text { Oligo } \\
\text { Tm }\end{array}$ & $\begin{array}{l}\text { Fwd } \\
\text { GC }\end{array}$ & $\begin{array}{l}\operatorname{Rev} \\
(\mathrm{GC})\end{array}$ & $\begin{array}{l}\text { Oligo } \\
\text { GC }\end{array}$ & $\begin{array}{l}\text { Target } \\
\text { size }\end{array}$ \\
\hline $\begin{array}{l}\text { CTCTTCTCGTT } \\
\text { CCTCATCACG }\end{array}$ & $\begin{array}{l}\text { CCAGACATTTT } \\
\text { GCTCTCAAGC }\end{array}$ & $\begin{array}{l}\text { TTGCTGCTG } \\
\text { CTTGACAG } \\
\text { ATT }\end{array}$ & 59.99 & 60.01 & 59.75 & 52.38 & 47.62 & 45 & 162 \\
\hline $\begin{array}{l}\text { AGTCAAGCCT } \\
\text { CTTCTCGTTC } \\
\text { C }\end{array}$ & $\begin{array}{l}\text { CCAGACATTTT } \\
\text { GCTCTCAAGC }\end{array}$ & $\begin{array}{l}\text { TTGCTGCTG } \\
\text { CTTGACAG } \\
\text { ATT }\end{array}$ & 60.01 & 60.01 & 59.75 & 52.38 & 47.62 & 45 & 170 \\
\hline $\begin{array}{l}\text { GTCAAGCCTC } \\
\text { TTCTCGTTCCT }\end{array}$ & $\begin{array}{l}\text { CCAGACATTTT } \\
\text { GCTCTCAAGC }\end{array}$ & $\begin{array}{l}\text { TTGCTGCTG } \\
\text { CTTGACAG } \\
\text { ATT }\end{array}$ & 60.01 & 60.01 & 59.75 & 52.38 & 47.62 & 45 & 169 \\
\hline $\begin{array}{l}\text { AGCCTCTTCT } \\
\text { CGTTCCTCAT } \\
\text { C }\end{array}$ & $\begin{array}{l}\text { CCAGACATTTT } \\
\text { GCTCTCAAGC }\end{array}$ & $\begin{array}{l}\text { TTGCTGCTG } \\
\text { CTTGACAG } \\
\text { ATT }\end{array}$ & 59.97 & 60.01 & 59.75 & 52.38 & 47.62 & 45 & 165 \\
\hline $\begin{array}{l}\text { GGGGGACAA } \\
\text { CCAATCACTA } \\
\text { AT }\end{array}$ & $\begin{array}{l}\text { TAACCTTTCCA } \\
\text { CATACCGCAG }\end{array}$ & $\begin{array}{l}\text { CAGTTACAC } \\
\text { CGGAAGCC } \\
\text { AAT }\end{array}$ & 59.93 & 60.01 & 59.99 & 47.62 & 47.62 & 50 & 278 \\
\hline
\end{tabular}

\section{Immunotherapy or Vaccine Design Module}

\section{Peptide-based therapeutics}

270 In the current study, we have predicted potential coronavirus epitopes which include B-cell

271 epitopes, T-cell epitopes, and MHC class I and class II binders. A total of 594 B-cell epitopes

272 and 966 T-cell epitopes predicted, which have $>=60 \%$ probability of correct prediction, are 
273 shown on the website with their peptide sequences. Additionally, 31,215 MHC class I and

274 17,635 MHC class II binders were predicted using ProPred 1 and ProPred, respectively, and 275 are displayed on the website. Apart from that, 117 experimentally validated IEDB epitopes

276 were mapped to corona antigens, which include B-cell and T-cell assays. The information 277 about assay include PubMed ID, epitope description, host organism, technique used, assay 278 group, and qualitative measure.

279 Potential Vaccine Candidates: In this study, we have suggested 17 epitopes that can act as 280 potential vaccine candidates against SARS-CoV-2 based on the results of different prediction 281 methods. The epitopes which were conserved among different prediction tools such as 282 LBtope, CTLPred, VaxinPAD, ProPred 1, and ProPred as well as experimentally validated 283 by IEDB, were chosen as potential vaccine candidates, as shown in Table 2. Besides, we have 284 linked these epitopes on our webserver, "CoronaVIR" to the source page of IEDB 285 (https://webs.iiitd.edu.in/raghava/coronavir/map.php). Further, by clicking on ID, user can 286 get complete information regarding the epitope, organism, antigen, assays used, etc. Out of 287 these 17 vaccine candidates, five epitopes, i.e. LQLPQGTTLPKGFYA, 288 VILLNKHIDAYKTFPPTEPKKDKKKK， EITVATSRTLS， GKGQQQQGQTV， and 289 SELVIGAVILR are reported in IEDB (B-cell, and T-cell assays), LBtope, CTLPred, 290 VaxinPAD, ProPred, and Propred 1.

291 Table 2: Potential Vaccine Candidates include IEDB (B-cell and T-cell assay), B-cell 292 epitope, T-cell epitope, Vaccine Adjuvants, MHC class I and II binders.

\begin{tabular}{|l|l|l|l|l|l|l|l|l|}
\hline Protein & Potential Vaccine Candidate & $\begin{array}{l}\text { IEDB } \\
\text { (T-cell) } \\
(\# \mathbf{1})\end{array}$ & $\begin{array}{l}\text { IEDB } \\
\text { (B-cell) } \\
(\# 1)\end{array}$ & $\begin{array}{l}\text { B-cell } \\
\text { epitope } \\
(\# 2)\end{array}$ & $\begin{array}{l}\text { T-cell } \\
\text { epitope } \\
(\# 3)\end{array}$ & $\begin{array}{l}\text { Vaccine } \\
\text { Adjuvants } \\
(\# 4)\end{array}$ & $\begin{array}{l}\text { MHC-I } \\
(\# 5)\end{array}$ & $\begin{array}{l}\text { MHC-II } \\
(\# 6)\end{array}$ \\
\hline $\begin{array}{l}\text { Nucleocapsid } \\
\text { Phosphoprotein }\end{array}$ & LQLPQGTTLPKGFYA & $\checkmark$ & $\checkmark$ & $\checkmark$ & $\checkmark$ & $x$ & $\checkmark$ & $\checkmark$ \\
\hline $\begin{array}{l}\text { Nucleocapsid } \\
\text { Phosphoprotein }\end{array}$ & $\begin{array}{l}\text { VILLNKHIDAYKTFPPTEPKK } \\
\text { DKKKK }\end{array}$ & $\checkmark$ & $\checkmark$ & $\checkmark$ & $\checkmark$ & $x$ & $\checkmark$ & $\checkmark$ \\
\hline $\begin{array}{l}\text { Membrane } \\
\text { Glycoprotein }\end{array}$ & EITVATSRTLS & $\checkmark$ & $\checkmark$ & $\checkmark$ & $\checkmark$ & $x$ & $\checkmark$ & $\checkmark$ \\
\hline $\begin{array}{l}\text { Nucleocapsid } \\
\text { Phosphoprotein }\end{array}$ & GKGQQQQGQTV & $\checkmark$ & $\checkmark$ & $\checkmark$ & $\checkmark$ & $x$ & $\checkmark$ & $x$ \\
\hline
\end{tabular}




\begin{tabular}{|c|c|c|c|c|c|c|c|c|}
\hline $\begin{array}{l}\text { Membrane } \\
\text { Glycoprotein }\end{array}$ & SELVIGAVILR & $x$ & $\checkmark$ & $\checkmark$ & $\checkmark$ & $\checkmark$ & $\checkmark$ & $\checkmark$ \\
\hline $\begin{array}{l}\text { Envelope } \\
\text { Protein }\end{array}$ & ALRLCAYCCN & $\checkmark$ & $x$ & $\checkmark$ & $\checkmark$ & $\checkmark$ & $\checkmark$ & $\checkmark$ \\
\hline ORF6 & HLVDFQVTIAEILLIIMR & $\checkmark$ & $x$ & $\checkmark$ & $\checkmark$ & $x$ & $\checkmark$ & $\checkmark$ \\
\hline $\begin{array}{l}\text { Envelope } \\
\text { Protein }\end{array}$ & $\begin{array}{l}\text { VFLLVTLAILTALRLCAYCC } \\
\text { NI }\end{array}$ & $\checkmark$ & $x$ & $\checkmark$ & $\checkmark$ & $\checkmark$ & $\checkmark$ & $\checkmark$ \\
\hline $\begin{array}{l}\text { Membrane } \\
\text { Glycoprotein }\end{array}$ & $\begin{array}{l}\text { NGTITVEELKKLLEQWNLVI } \\
\text { GFLFL }\end{array}$ & $\checkmark$ & $x$ & $\checkmark$ & $\checkmark$ & $\checkmark$ & $\checkmark$ & $\checkmark$ \\
\hline $\begin{array}{l}\text { Membrane } \\
\text { Glycoprotein }\end{array}$ & $\begin{array}{l}\text { ASFRLFARTRSMWSFNPETNI } \\
\text { LLNVPLHGT }\end{array}$ & $\checkmark$ & $x$ & $x$ & $\checkmark$ & $\checkmark$ & $\checkmark$ & $\checkmark$ \\
\hline $\begin{array}{l}\text { Membrane } \\
\text { Glycoprotein }\end{array}$ & SRYRIGNYKL & $\checkmark$ & $x$ & $x$ & $\checkmark$ & $\checkmark$ & $\checkmark$ & $\checkmark$ \\
\hline ORF8 & RCSFYEDFLEYHDVR & $x$ & $x$ & $\checkmark$ & $\checkmark$ & $\checkmark$ & $\checkmark$ & $\checkmark$ \\
\hline ORF6 & IWNLDYIINLIIKNLSKSLT & $x$ & $x$ & $\checkmark$ & $\checkmark$ & $x$ & $\checkmark$ & $\checkmark$ \\
\hline $\begin{array}{l}\text { Surface } \\
\text { Glycoprotein }\end{array}$ & $\begin{array}{l}\text { SETKCTLKSFTVEKGIYQTSN } \\
\text { F }\end{array}$ & $x$ & $x$ & $\checkmark$ & $\checkmark$ & $x$ & $\checkmark$ & $\checkmark$ \\
\hline ORF8 & $\begin{array}{l}\text { MKFLVFLGIITTVAAFHQECS } \\
\text { LQSCTQ }\end{array}$ & $x$ & $x$ & $\checkmark$ & $\checkmark$ & $x$ & $\checkmark$ & $\checkmark$ \\
\hline ORF3a & DGTTSPISE & $x$ & $x$ & $\checkmark$ & $\checkmark$ & $x$ & $\checkmark$ & $x$ \\
\hline ORF3a & $\begin{array}{l}\text { SKIITLKKRWQLALSKGVHF } \\
\text { VCNLLL }\end{array}$ & $x$ & $x$ & $\checkmark$ & $\checkmark$ & $\checkmark$ & $\checkmark$ & $x$ \\
\hline
\end{tabular}

293 \#1: IEDB, \#2: LBtope, \#3: CTLPred, \#4: VaxinPAD, \#5: ProPred 1, \#6: ProPred

294 Mapping and Validation of Predicted Epitopes in strains of various Countries

295 Next, we aimed to validate our peptide-based potential vaccine candidates in other strains

296 across the globe. Towards this, we have randomly taken six different genomes from different 
countries available for SARS-COV-2 strains from NCBI with Accession IDs MT012098,

298 MT050493, MT066156, MT159711, MT246462, and MT233519. Subsequently, we mapped

299 our top five peptide-based vaccine candidates. Mapping results showed that these epitopes

300 are present in all these strains, shown in Table 3. These results indicate that theses vaccine

301 candidates can be implemented widely across the globe.

302

303 Table 3: Mapping and Validation of predicted Epitopes in SARS-COV-3 strains from other parts of Globe.

\begin{tabular}{|c|c|c|c|c|c|c|c|}
\hline Epitope & Protein & \multicolumn{6}{|c|}{ Accession IDs and Country } \\
\hline- & - & MT012098 & MT050493 & MT066156 & MT159711 & MT246462 & MT233519 \\
\hline- & - & India & India & Italy & USA & USA & Spain \\
\hline LQLPQGTTLPKGFYA & $\begin{array}{l}\text { Nucleocapsid } \\
\text { Phosphoprotein }\end{array}$ & Yes & Yes & Yes & Yes & Yes & Yes \\
\hline $\begin{array}{l}\text { VILLNKHIDAYKTFPP } \\
\text { TEPKKDKKKK }\end{array}$ & $\begin{array}{l}\text { Nucleocapsid } \\
\text { Phosphoprotein }\end{array}$ & Yes & Yes & Yes & Yes & Yes & Yes \\
\hline EITVATSRTLS & $\begin{array}{l}\text { Membrane } \\
\text { Glycoprotein }\end{array}$ & Yes & Yes & Yes & Yes & Yes & Yes \\
\hline
\end{tabular}

305

306 Nucleotide-based adjuvants: First, we predicted a large numbers of nucleotide-based

307 vaccine adjuvants for each of ten proteins using VaccineDA, as given in Table S2 and on the

308 webserver (https://webs.iiitd.edu.in/raghava/coronavir/adj.php). Subsequently, top ten

309 potential vaccine adjuvants candidates selected based on the SVM-score, enlisted in Table 4.

310 Out of them, oligodeoxynucleotide of Orf8 and Orf1ab, i.e.

311 "GCGTTGTTCGTTCTATGAAGACTTTTTAGA" "and

312 "ACGTTAATACGTTTTCATCAACTTTTAACG" withstand to be exceptionally

313 immunomodulator with the SVM score of 1.885 and 1.537 , respectively.

314 Table 4: List of potential nucleotide-based vaccine adjuvants, predicted by the

315 VaccineDA for the 10 proteins from SARS-CoV-2. 


\begin{tabular}{|c|c|c|c|c|c|c|}
\hline Protein name & Sequence & SVM Score & Length & $\begin{array}{l}\text { Mol. } \\
\text { Wt. }\end{array}$ & $\mathrm{Tm}$ & $\begin{array}{l}\mathrm{GC} \\
\text { content } \\
(\%)\end{array}$ \\
\hline Orf8 & $\begin{array}{l}\text { GCGTTGTTCGTTCTATGAA } \\
\text { GACTTTTTAGA }\end{array}$ & 1.885 & 30 & 9233.09 & 57.52 & 36.67 \\
\hline Orf1ab & $\begin{array}{l}\text { ACGTTAATACGTTTTCATC } \\
\text { AACTTTTAACG }\end{array}$ & 1.537 & 30 & 9130.04 & 54.79 & 30 \\
\hline $\begin{array}{l}\text { Envelope } \\
\text { protein }\end{array}$ & $\begin{array}{l}\text { ACGTTAATAGTTAATAGC } \\
\text { GTACTTCTTTTT }\end{array}$ & 1.492 & 30 & 9176.08 & 53.42 & 26.67 \\
\hline Orf6 & $\begin{array}{l}\text { ATTATGAGGACTTTTAAA } \\
\text { GTTTCCATTTGG }\end{array}$ & 1.33 & 30 & 9241.12 & 54.79 & 30 \\
\hline $\begin{array}{l}\text { Surface } \\
\text { glycoprotein }\end{array}$ & $\begin{array}{l}\text { ACTAATGTCTATGCAGAT } \\
\text { TCATTTGTAATT }\end{array}$ & 1.265 & 30 & 9185.09 & 53.42 & 26.67 \\
\hline Orf3a & $\begin{array}{l}\text { TTCTCTATCTTTATGCTTT } \\
\text { AGTCTACTTCT }\end{array}$ & 1.248 & 30 & 9044.96 & 54.79 & 30 \\
\hline $\begin{array}{l}\text { Nucleocapsid } \\
\text { glycoprotein }\end{array}$ & $\begin{array}{l}\text { GCGTTGTTCGTTCTATGAA } \\
\text { GACTTTTTAGA }\end{array}$ & 1.085 & 30 & 9246.08 & 61.62 & 46.67 \\
\hline $\begin{array}{l}\text { Membrane } \\
\text { glycoprotein }\end{array}$ & $\begin{array}{l}\text { TAACTTTAGCTTGTTTTGT } \\
\text { GCTTGCTGCTG }\end{array}$ & 1.068 & 30 & 9191.04 & 58.89 & 40 \\
\hline Orf7a & $\begin{array}{l}\text { CTCTAGCTGATAACAAAT } \\
\text { TTGCACTGACTT }\end{array}$ & 0.797 & 30 & 9140.03 & 57.52 & 36.67 \\
\hline Orf10 & $\begin{array}{l}\text { AACGTTTTCGCTTTTCCGT } \\
\text { TTACGATATAT }\end{array}$ & 0.796 & 30 & 9128.02 & 56.15 & 33.33 \\
\hline
\end{tabular}

316

\section{RNA therapeutics}

318 This section maintains a list of potential siRNAs that can serve as candidates for RNA based

319 therapeutics. As shown in Table 5, these siRNAs can suppress or degrade different genes of

320 SARS-CoV-2 with high efficacy (>0.80); each siRNA has high target accessibility (>0.6).

321 Here, we have shown only the top 10 siRNA that can serve as a therapeutic candidate against

322 COVID-19. Among them, Orf1ab protein is shown to be the top protein with the predicted

323 antisense sequence of siRNA "AAAUUGAUCGUACAACACG" and mRNA target

324 sequence "CGUGUUGUACGAUCAAUUU" with target accessibility of 0.636979 and

325 efficacy of 1.129115. 


\begin{tabular}{|c|c|c|c|c|c|}
\hline Protein name & $\begin{array}{l}\text { Antisense Sequences of } \\
\text { siRNA }\end{array}$ & $\begin{array}{l}\text { Position on } \\
\text { mRNA }\end{array}$ & mRNA target sequence & $\begin{array}{l}\text { Target } \\
\text { accessibility }\end{array}$ & Efficacy \\
\hline Orf1ab protein & $\begin{array}{l}\text { AAAUUGAUCGUACA } \\
\text { ACACG }\end{array}$ & 12 & $\begin{array}{l}\text { CGUGUUGUACGAUCA } \\
\text { AUUU }\end{array}$ & 0.637 & 1.129 \\
\hline Orf3a protein & $\begin{array}{l}\text { AACAACAACAGCAA } \\
\text { GUUGC }\end{array}$ & 11 & $\begin{array}{l}\text { GCAACUUGCUGUUGU } \\
\text { UGUU }\end{array}$ & 0.979 & 1.080 \\
\hline $\begin{array}{l}\text { Surface } \\
\text { protein }\end{array}$ & $\begin{array}{l}\text { UAAGAUUAACACAC } \\
\text { UGACU }\end{array}$ & 3 & $\begin{array}{l}\text { AGUCAGUGUGUUAAU } \\
\text { CUUA }\end{array}$ & 0.722 & 1.078 \\
\hline $\begin{array}{l}\text { Envelope } \\
\text { protein }\end{array}$ & $\begin{array}{l}\text { UUAACUAUUAACGU } \\
\text { ACCUG }\end{array}$ & 10 & $\begin{array}{l}\text { CAGGUACGUUAAUAG } \\
\text { UUAA }\end{array}$ & 0.768 & 1.053 \\
\hline Orf6 protein & $\begin{array}{l}\text { UUUAUUCUCAGUUA } \\
\text { GUGAC }\end{array}$ & 12 & $\begin{array}{l}\text { GUCACUAACUGAGAA } \\
\text { UAAA }\end{array}$ & 0.654 & 1.034 \\
\hline $\begin{array}{l}\text { Nucleocapsid } \\
\text { protein }\end{array}$ & $\begin{array}{l}\text { UUUGUAUGCGUCAA } \\
\text { UAUGC }\end{array}$ & 8 & $\begin{array}{l}\text { GCAUAUUGACGCAUAC } \\
\text { AAA }\end{array}$ & 0.676 & 1.033 \\
\hline $\begin{array}{l}\text { Membrane } \\
\text { protein }\end{array}$ & $\begin{array}{l}\text { AAACAAGCUAAAGU } \\
\text { UACUG }\end{array}$ & 3 & $\begin{array}{l}\text { CAGUAACUUUAGCUU } \\
\text { GUUU }\end{array}$ & 0.673 & 1.010 \\
\hline Orf10 protein & $\begin{array}{l}\text { UAACUACAUCUACU } \\
\text { UGUGC }\end{array}$ & 4 & $\begin{array}{l}\text { GCACAAGUAGAUGUA } \\
\text { GUUA }\end{array}$ & 0.723 & 0.981 \\
\hline Orf8 protein & $\begin{array}{l}\text { UGAUACUCUAAAAA } \\
\text { GUCUU }\end{array}$ & 3 & $\begin{array}{l}\text { AAGACUUUUUAGAGU } \\
\text { AUCA }\end{array}$ & 0.947 & 0.923 \\
\hline Orf7a protein & $\begin{array}{l}\text { AAAUUGAGUGCUAA } \\
\text { AGCAA }\end{array}$ & 11 & $\begin{array}{l}\text { UUGCUUUAGCACUCAA } \\
\text { UUU }\end{array}$ & 0.791 & 0.819 \\
\hline
\end{tabular}

\section{Drug Designing Module}

330 Drug Targets: In previous studies, it has been shown that some of the potential viral drug

331 targets include non-structural proteins (nsp) (papain-like protease, RNA-dependent RNA

332 polymerase, helicase, etc.), structural proteins (nucleocapsid protein, envelope protein, spike

333 protein) and other accessory proteins (47, 48). As SARS-CoV-2 also has a positive sense

334 single-stranded RNA as its genetic material, therefore, we compiled this information about

335 these targets for SARS-COV-2. Thus, we selected the potential drug targets, which are key

336 components of the COVID-19 infection lifecycle. This includes proteins involved in the viral

337 entry into the host cell, viral replication machinery, and viral RNA synthesis. The 
information includes Accession ID, Gene encoding the protein, Locus Tag, Source of the

339 protein, Protein sequence, and identical proteins. All this information can be accessed from

340 the webserver (https://webs.iiitd.edu.in/raghava/coronavir/dt.php).

341 3D Structure: As per RCSB-PDB data till 25 March, more than 90 crystallized structures 342 related to SARS-CoV-2 have been reported

343 (http://www.rcsb.org/pdb/results/results.do?tabtoshow=Current\&qrid=D12523A6\&startAt=0

344 \&resultsperpage=93). On our webserver, firstly we maintained structures of some of the 345 important ones include crystallized structures of spike glycoprotein (PDB ID: 6VSB), HR2 346 domain of 2019-nCoV (PDB ID: 6LVN), post-fusion core of SARS-CoV-2 S2 subunit (PDB 347 ID: 6LXT) and crystal structure of main protease in association with an inhibitor N3 (PDB 348 ID: 6LU7). Besides, Phyre2.0 server (7) was used for modeling the structures of various other 349 proteins. Here, we modeled ten important proteins that include RNA-dependent RNA350 polymerase, Envelop Protein, membrane glycoprotein, nucleocapsid phosphoprotein, and 351 ORF3a protein, etc. which could be potential drug targets, as represented at webserver 352 (https://webs.iiitd.edu.in/raghava/coronavir/struct2.php). We observed that our modeled 353 structures were of good quality as for most of the protein residues are present in the allowed 354 region (here we consider most favored regions, additional allowed regions and generously 355 allowed regions). Also, the QMEAN score, which is measured in the range of 0-1, was found to be present above 0.5 for most of the residues. Overall, the model is good enough for drug designing studies. Detail information of the structures such as template information, the percent identity of the query sequence with the template sequence, type of fold present in the template, etc. Users can download the structures and the Ramachandran Plot from the link

360 https://webs.iiitd.edu.in/raghava/coronavir/struct.php.

361 Potential Drug Molecules: We mapped the SARS-CoV-2 genome to existing FDA approved 362 drugs present in the DrugBank. This leads to the identification of drugs (e.g., camostat 363 myselate, Ritonavir, Lopinavir, and Remdesivir, Chloroquine) that has potential to treat 364 COVID-19. These drugs have been previously proposed to treat various viral infections (4953). For example, Kaletra is an approved combination of HIV protease inhibitors ritonavir, and lopinavir is currently under clinical trials for treating COVID-19 infection, and in some patients, it has shown some promising results. Further, we have also performed the docking procedure by docking the putative drugs on the predicted structures of the targets from SARS-CoV-2. To compare our docked structures, we have also docked the drugs with their targets given in Drugbank (38-40), whose structures are available in PBD (REF). We found 
371 that gs-6620, which is similar to Remdesivir, got the highest score among all. Table 6

372 represents a list of some of the potential drugs along with their target information. We have

373 also compiled the list of a drug which have been predicted computationally or are re-

374 purposed drugs from different studies, is provided at our website. Besides, Dong L et al 2020

375 suggested the five antiviral drugs included in the Guidelines (version 6) for treatment of

376 COVID-19, available on the webserver (11). Users can browse those drugs by clicking on the

377 "Click to view complete file" tab provided at the website

378 https://webs.iiitd.edu.in/raghava/coronavir/dm.php.

379

380 Table 6. List of potential drugs which could be used for treating COVID-19 infection

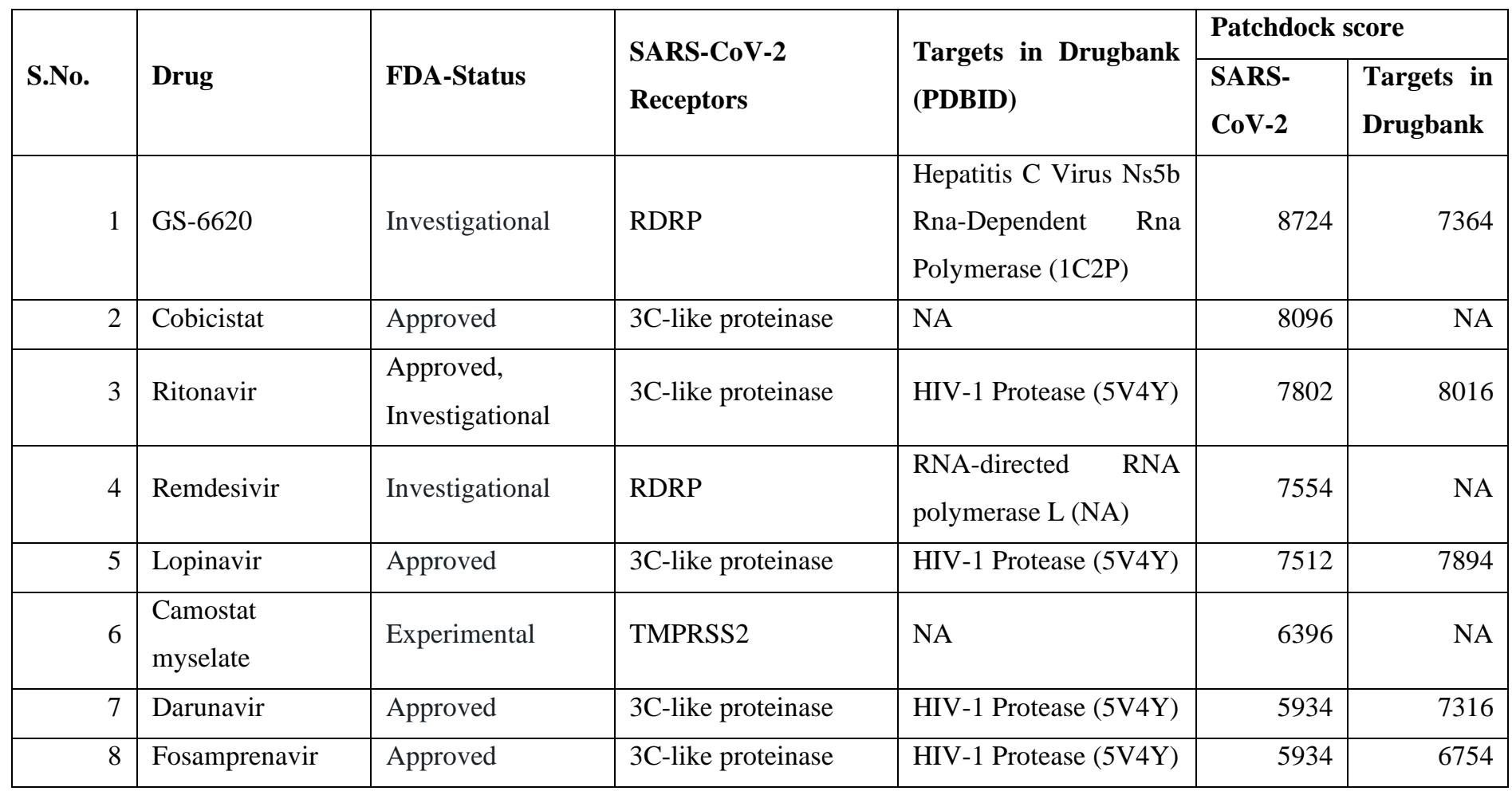

381

382 Drug Delivery: We predicted CPPs corresponding to 10 proteins of the SARS-CoV-2 using

383 CellPPD server. These peptides can be used for drug delivery. In addition, these peptides can

384 be used to understand virus-host interaction. User can also get detailed information like SVM

385 score, physic-chemical properties include hydrophobicity, hydrophilicity, charge, molecular

386 weight, etc. at the website https://webs.iiitd.edu.in/raghava/coronavir/dd.php.

387 
Currently, the quest for effective vaccine design against COVID-19 is increasing among research groups. Similar analyses for vaccine designing are being conducted or already reported in various studies. For instance, a report by Ramaiah A et al. in February 2020,

392 proposed eight CD4 T-cell epitopes in the S, E, M and N proteins based on the Asia and

393 Asia-Pacific Region population using computational approach (55). These epitopes can be recognized by HLA-DR alleles. Besides, recently Ahmed et al also suggested potential vaccine candidates, i.e. a set of $\mathrm{B}$ cell and $\mathrm{T}$ cell epitopes derived from $\mathrm{S}$ and $\mathrm{N}$ proteins for SARS-COV-2 based on the analysis of experimentally validated epitopes of SARS-COV having sequence similarity with SARS-COV-2 (56). Furthermore, Marek Prachar et al proposed 174 SARS-CoV-2 epitopes that are in vitro validated to bind stably to 11 HLA allotypes include 10 HLA class I and one HLA class II based on using the computational and in vitro analysis (57). Furthermore, various studies predicted multi-epitopes or numerous vaccine candidates for SARS-COV-2 infections using the computational approach as represented by different pre-prints (58-62). The question arises, why another study for designing an epitope-based vaccine against COVID-19. Best of our knowledge, none of the existing studies identify epitopes that can activate both innate and adaptive immune system. In our study, we identified peptides that can activate both arms of the immune system as well as identify promiscuous MHC binders and vaccine adjuvants. As shown in Table 2, potential peptides identified in this study have almost all required properties for an effective vaccine. Besides, top five vaccine candidates from our study also mapped on six SARS-COV-2 strains from different parts of world. This indicates, their universal utility aspect. Thus, additional features of our vaccine module will complement existing studies in fighting against COVID19.

412 Knowing the fact of the importance of drugs in curbing the COVID-19, numerous researchers

413 focused on the elucidation of potent drugs. In this study, we compile these studies to provide 414 information from a single source. Various reports suggested repurposing of different drugs 415 for COVID-19 patients (48, 63, 64). A molecular docking study by Elfiky AA suggested 416 Ribavirin, Remdesivir, Sofosbuvir, Galidesivir, and Tenofovir as potent drugs against SARS417 CoV-2 as tightly bound to its RdRP (65). Moreover, this study also proposed the IDX-184, 418 Setrobuvir, and YAK as antiviral treatments for COVID-19. Further, an in vitro study by 419 Manli Wang et al showed the effectiveness of Remdesivir and Chloroquine in the controlling 420 the of COVID-19 infection (66). Importantly, a study by Chu CM et al on 41 patients with 421 COVID-19 that were treated with a combination of Lopinavir/Ritonavir and Ribavirin 
showed favorable outcome in comparison to the 111 patients treated with Ribavirin only and placebo controls; thus suggested the clinical utility (67). Moreover, one of the studies is focussed on the development of COVID-19 Docking Server (68). This tool predicts the binding modes between COVID-19 targets and the ligands including small molecules, peptide and antibody. Besides, Dong L et al. summarizes the antiviral drugs and their efficacy included in the Guidelines (version 6) for treatment of COVID-19 (11). Inconclusively, all these reports targeted one or other aspect of the various drugs in combating the COVID-19. In our study, we have tried to cover the holistic view of the drug design or available drugs to curb the COVID-19. Therefore, we have predicted drug targets, their structure, compiled possible drug molecules from the literature. Besides, to understand host-virus interaction, we have also predicted CPP from viral proteins. One of our goals is the feasibility of identified candidates for the experimental validation. Therefore, we prioritized these vaccine or drug candidates as a minimum manageable subset. Eventually, it will facilitate the possibility of their implementation in real life.

\section{Discussion and Conclusion}

The ongoing severe pandemic outbreak of COVID-19 is the major concern across the globe. Currently, COVID-19 has affected 205 countries and territories with one international conveyance, i.e. the Diamond Princess cruise ship harbored in Yokohama, Japan, as of April 3, 2020 (https://www.worldometers.info/coronavirus/). The containment of COVID-19 and the management of patients is the need of the hour. To tackle this medical emergency, numerous scientists are extensively working on the characterization of SARS-CoV-2 for accurate diagnosis and designing the appropriate vaccines and therapies to cure COVID-19 patients. In addition, various organizations are also actively involved in generating the vital statistics and information about the COVID-19 outbreak. This generates plenty of data or information in the form of widely spread literature, resources, videos, etc. One of the major challenges is to manage/accumulate this information at a single platform in a user-friendly manner, to make it approachable to the wider audience such as the scientific community, clinicians, etc. for the containment of COVID-19 patients. Since, the delay in diagnosis and the lack of effective drugs and vaccines for COVID-19 results in increasing the mortality rate day by day (69). There is a need to accelerate the research in the development of adequate vaccines and drugs. Hence, the present study is an attempt to compile this widespread information associated with SARS-CoV-2 or COVID-19 at a single user-friendly web-based 
platform named "CoronaVIR" (https://webs.iiitd.edu.in/raghava/coronavir/), along with predicted novel potential diagnostic, vaccine and drug candidates based on literature and bioinformatics analysis.

In the CoronaVIR, we have integrated mainly four modules which include "Genomics", "Diagnosis", "Immunotherapy", and "Drug Designing". The "Genomics" module provides 53 whole-genome sequences from various countries and sequences of 10 proteins, etc. This will facilitate the users/researchers for the genomic-analysis of SARS-CoV-2 to scrutinize vital information of structural and functional components, eventually to design vaccine, drug molecules. The "Diagnosis" module provides detailed information regarding currently-in-use diagnostic tests. Additionally, we have predicted novel five universal primers candidate sets for the diagnosis of COVID-19 based on 53 genomic sequences of SARS-CoV-2 strains of different parts of the globe. These diagnostic primers need experimental validation as they are designed by Insilco analysis only. Further, the "Immunotherapy" module of CoronaVIR maintains various peptide and RNA-based immunotherapeutic candidates for COVID-19. In the current study, we have proposed 17 potential vaccine candidates that can activate the immune system based on our bioinformatics analysis. Importantly, five peptide sequences, i.e. LQLPQGTTLPKGFYA, VILLNKHIDAYKTFPPTEPKKDKKKK, EITVATSRTLS, GKGQQQQGQTV, and SELVIGAVILR are predicted by most of the immuno-informatics tool such as LBtope, CTLPred, VaxinPAD, ProPred, and Propred 1 and also reported in IEDB. This analysis indicates that these epitopes have potential of B-cell, T-cell activation with MHC-binding and vaccine adjuvant capability; eventually can activate almost all the arms of our immune system. Furthermore, these five vaccine candidates are also mapped on six SARS-COV-2 strains from different parts of globe. This reveals their utility on universal aspects. Besides peptide-based vaccine candidates, we have also discovered siRNA-based therapeutics and nucleotide-based vaccine adjuvants for COVID-19 using insilico approach. Eventually, experimental researchers can further explore these potential vaccine candidates to confirm their clinical utility. Apart from that, Drugs are the key means to combat this global disaster of COVID-19. Hence, the "Drug Designing" module is integrated to manage information of nine potential drug targets, their structures, number of drug molecules, drug delivery peptide-based vehicles (CPP). Recently, Wang et al. has shown in their study that a human monoclonal antibody 47D11 binds to SARS-CoV-2 and SARS-CoV, and potently 
act as therapeutics to treat COVID-19 patients. Although, clinical validation is still needed to confirm their potential application in combating COVID-19.

Taken together, CoronaVIR is a comprehensive web-based platform, which accommodates widely scattered information of different aspects, i.e. genomics, diagnosis, therapeutics of the SARS-CoV-2 in a user-friendly manner. We anticipate this would facilitate the researchers involved in managing the COVID-19. Moreover, the novel suggested potential diagnostic, vaccine and therapeutic candidates based on insilico analysis might further help in designing effective diagnostic tools and vaccines for COVID-19, and hence eventually help in combating this COVID-19 medical disaster.

\section{Competing interests}

The authors declare no competing financial and non-financial interests.

\section{Acknowledgement}

The authors acknowledge funding from J. C. Bose National Fellowship from Department of Science \& Technology (DST), India with Grant Number SRP076. H.K. and S.P. are thankful to Council of Scientific and Industrial Research (CSIR), India, Department of Biotechnology (DBT), respectively for providing fellowship. N.S. and A.D. are thankful to Department of Science \& Technology (DST), India for providing fellowship. D.K., P.A., and C.A. are thankful to Indraprastha Institute of Information Technology, Delhi (IIITD), New Delhi, India for providing fellowships. L.M. is thankful to Department of Science \& Technology (DST), India for providing NPDF fellowship. The funders had no role in study design, data collection and analysis, decision to publish, or preparation of the manuscript.

\section{Authors Contributions}

S.P., D.K., H.K., N.S., A.D., S.S. collected the data and processed the datasets. S.P., H.K., D.K., N.S., A.D., S.S., P.A., C.A., and L.M. analyzed and predicted candidates. D.K. and H.K., developed Genomics module. H.K. and L.A., developed Diagnosis module. S.P., N.S., A.D., and D.K. developed Immunotherapy module. S.P., S.S., and P.A. designated Drug Designing module. S.P., D.K., H.K., A.D., P.A., C.A., and G.P.S.R created the back-end server and front-end user interface. S.P., H.K., D.K., N.S., A.D., P.A., L.M., and G.P.S.R. analyzed the results. S.P. H.K., D.K., C.A., N.S., and G.P.S.R penned the manuscript. 
515 G.P.S.R. conceived and coordinated the project, facilitated in the interpretation and data 516 analysis and gave overall supervision to the project. All authors have read and approved the

517 final manuscript.

\section{$518 \quad$ References}

519 1. Ecdc Cluster of pneumonia cases caused by novel coronavirus, Wuhan, China - January 5202020 .

521

522

523

524

525

526

527

528

529

530

531

532

533

534

535

536

537

2. Zhou,P., Yang,X. Lou, Wang,X.G., Hu,B., Zhang,L., Zhang,W., Si,H.R., Zhu,Y., Li,B., Huang,C.L., et al. (2020) A pneumonia outbreak associated with a new coronavirus of probable bat origin. Nature, 579, 270-273.

3. Zhu,N., Zhang,D., Wang,W., Li,X., Yang,B., Song,J., Zhao,X., Huang,B., Shi,W., Lu,R., et al. (2020) A novel coronavirus from patients with pneumonia in China, 2019. N. Engl. J. Med., 382, 727-733.

4. Lu,R., Zhao,X., Li,J., Niu,P., Yang,B., Wu,H., Wang,W., Song,H., Huang,B., Zhu,N., et al. (2020) Genomic characterisation and epidemiology of 2019 novel coronavirus: implications for virus origins and receptor binding. Lancet, 395, 565-574.

5. World Map | CDC.

6. Chan,J.F.W. and Azhar,E.I. (2016) Coronavirus-drug discovery and therapeutic options First coplete genome sequence of circulating dengue virus serotypr 3 in Jeddah Saudi Arabia View project hcv and csc View project. Nat. Publ. Gr., 15, 327-347.

7. Kelley,L.A., Mezulis,S., Yates,C.M., Wass,M.N. and Sternberg,M.J.E. (2015) The Phyre2 web portal for protein modeling, prediction and analysis. Nat. Protoc., 10, 845-858.

8. Khan,M., Kazmi,S., Bashir,A. and Siddique,N. (2020) COVID-19 infection: origin, transmission, and characteristics of human coronaviruses. J. Adv. Res., 24, 91-98. 
coronavirus from Wuhan: An analysis based on decade-long structural studies of SARS.

10. Cascella,M., Rajnik,M., Cuomo,A., Dulebohn,S.C. and Di Napoli,R. (2020) Features, Evaluation and Treatment Coronavirus (COVID-19) StatPearls Publishing.

11. Dong,L., Hu,S. and Gao,J. (2020) Discovering drugs to treat coronavirus disease 2019 (COVID-19). Drug Discov. Ther., 14, 58-60.

12. Covid-19 clinical trials analysed by GlobalData in terms of participant size.

13. NIH clinical trial of remdesivir to treat COVID-19 begins | National Institutes of Health 547 (NIH).

14. Chang,Y.-C., Tung,Y.-A., Lee,K.-H., Chen,T.-F., Hsiao,Y.-C., Chang,H.-C., Hsieh,T.-T., 549 Su,C.-H., Wang,S.-S., Yu,J.-Y., et al. (2020) Potential Therapeutic Agents for COVID19 Based on the Analysis of Protease and RNA Polymerase Docking. 10.20944/PREPRINTS202002.0242.V1.

15. Hodgson,J. (2020) The pandemic pipeline. Nat. Biotechnol., 10.1038/d41587-020-00005-

16. Dong,E., Du,H. and Gardner,L. (2020) An interactive web-based dashboard to track COVID-19 in real time. Lancet. Infect. Dis., 10.1016/S1473-3099(20)30120-1.

17. NCBI Virus.

18. NCBI Virus.

19. GitHub - primer3-org/primer3: Primer3 is a command line tool to select primers for polymerase chain reaction (PCR). 
562

563

564

565

566

567

568

569

570

571

572

573

574

575

576

577

578

579

580

581

582

583

584

21. Kim,H., Kang,N., An,K., Kim,D., Koo,J. and Kim,M.-S. (2017) MRPrimerV: a database of PCR primers for RNA virus detection. Nucleic Acids Res., 45, D475-D481.

22. Singh,H., Ansari,H.R. and Raghava,G.P.S. (2013) Improved method for linear B-cell epitope prediction using antigen's primary sequence. PLoS One, 8, e62216.

23. Gupta,S., Ansari,H.R., Gautam,A., Open Source Drug Discovery Consortium and Raghava,G.P.S. (2013) Identification of B-cell epitopes in an antigen for inducing specific class of antibodies. Biol. Direct, 8, 27.

24. Xu,G.J., Kula,T., Xu,Q., Li,M.Z., Vernon,S.D., Ndung'u,T., Ruxrungtham,K., Sanchez,J., Brander,C., Chung,R.T., et al. (2015) Viral immunology. Comprehensive serological profiling of human populations using a synthetic human virome. Science, 348, aaa0698.

25. Amat-ur-Rasool,H., Saghir,A. and Idrees,M. (2015) Computational prediction and analysis of envelop glycoprotein epitopes of DENV-2 and DENV-3 Pakistani isolates: a first step towards Dengue vaccine development. PLoS One, 10, e0119854.

26. Legutki,J.B., Zhao,Z.-G., Greving,M., Woodbury,N., Johnston,S.A. and Stafford,P. (2014) Scalable high-density peptide arrays for comprehensive health monitoring. Nat. Commun., 5, 4785.

27. Jahangiri,A., Rasooli,I., Owlia,P., Fooladi,A.A.I. and Salimian,J. (2017) In silico design of an immunogen against Acinetobacter baumannii based on a novel model for native structure of Outer membrane protein A. Microb. Pathog., 105, 201-210.

28. Gupta,A.K., Kaur,K., Rajput,A., Dhanda,S.K., Sehgal,M., Khan,M.S., Monga,I., Dar,S.A., Singh,S., Nagpal,G., et al. (2016) ZikaVR: An Integrated Zika Virus Resource for Genomics, Proteomics, Phylogenetic and Therapeutic Analysis. Sci. Rep., 6, 32713. 
29. Dhanda,S.K., Chaudhary,K., Gupta,S., Brahmachari,S.K. and Raghava,G.P.S. (2016) A web-based resource for designing therapeutics against Ebola Virus. Sci. Rep., 6, 24782.

30. McIntyre,G.J., Groneman,J.L., Yu,Y.-H., Jaramillo,A., Shen,S. and Applegate,T.L. (2009) 96 shRNAs designed for maximal coverage of HIV-1 variants. Retrovirology, 6 , 55.

31. Katoh,T. and Suzuki,T. (2007) Specific residues at every third position of siRNA shape its efficient RNAi activity. Nucleic Acids Res., 35, e27.

32. Ahmed,F. and Raghava,G.P.S. (2011) Designing of highly effective complementary and mismatch siRNAs for silencing a gene. PLoS One, 6, e23443.

33. Cascella,M., Rajnik,M., Cuomo,A., Dulebohn,S.C. and Di Napoli,R. (2020) Features, Evaluation and Treatment Coronavirus (COVID-19) StatPearls Publishing.

34. Guo,Y.-R., Cao,Q.-D., Hong,Z.-S., Tan,Y.-Y., Chen,S.-D., Jin,H.-J., Tan,K.-S., Wang,D.Y. and Yan,Y. (2020) The origin, transmission and clinical therapies on coronavirus disease 2019 (COVID-19) outbreak - an update on the status. Mil. Med. Res., 7.

35. Laskowski,R.A., Rullmann,J.A.C., MacArthur,M.W., Kaptein,R. and Thornton,J.M. (1996) AQUA and PROCHECK-NMR: Programs for checking the quality of protein structures solved by NMR. J. Biomol. NMR, 8, 477-486.

36. Laskowski,R.A., MacArthur,M.W., Moss,D.S. and Thornton,J.M. (1993) PROCHECK: a program to check the stereochemical quality of protein structures. J. Appl. Crystallogr., 26, 283-291.

37. Benkert,P., Künzli,M. and Schwede,T. (2009) QMEAN server for protein model quality estimation. Nucleic Acids Res., 37, W510-4.

38. Wishart,D.S., Feunang,Y.D., Guo,A.C., Lo,E.J., Marcu,A., Grant,J.R., Sajed,T., Johnson,D., Li,C., Sayeeda,Z., et al. (2018) DrugBank 5.0: a major update to the 
610

611

612

613

614

615

616

617

618

619

620

621

622

623

624

625

626

627

628

629

630

631

632

39. Knox,C., Law,V., Jewison,T., Liu,P., Ly,S., Frolkis,A., Pon,A., Banco,K., Mak,C., Neveu,V., et al. (2011) DrugBank 3.0: a comprehensive resource for 'omics' research on drugs. Nucleic Acids Res., 39, D1035-41.

40. Law,V., Knox,C., Djoumbou,Y., Jewison,T., Guo,A.C., Liu,Y., Maciejewski,A., Arndt,D., Wilson,M., Neveu,V., et al. (2014) DrugBank 4.0: shedding new light on drug metabolism. Nucleic Acids Res., 42, D1091-7.

41. Duhovny,D., Nussinov,R. and Wolfson,H.J. (2002) Efficient unbound docking of rigid molecules. In Lecture Notes in Computer Science (including subseries Lecture Notes in Artificial Intelligence and Lecture Notes in Bioinformatics). Springer Verlag, Vol. 2452, pp. 185-200.

42. Schneidman-Duhovny,D., Inbar,Y., Nussinov,R. and Wolfson,H.J. (2005) PatchDock and SymmDock: servers for rigid and symmetric docking. Nucleic Acids Res., 33, W363-7.

43. PyMOL | pymol.org.

44. Chauhan,A., Tikoo,A., Kapur,A.K. and Singh,M. (2007) The taming of the cell penetrating domain of the HIV Tat: Myths and realities. J. Control. Release, 117, 148162.

45. Rizzuti,M., Nizzardo,M., Zanetta,C., Ramirez,A. and Corti,S. (2015) Therapeutic applications of the cell-penetrating HIV-1 Tat peptide. Drug Discov. Today, 20, 76-85.

46. Gautam,A., Chaudhary,K., Kumar,R., Sharma,A., Kapoor,P., Tyagi,A., Open source drug discovery consortium and Raghava,G.P.S. (2013) In silico approaches for designing highly effective cell penetrating peptides. J. Transl. Med., 11, 74.

47. Beck,B.R., Shin,B., Choi,Y., Park,S. and Kang,K. (2020) Predicting commercially available antiviral drugs that may act on the novel coronavirus (2019-nCoV), Wuhan, 
633

634

635

636

637

638

639

640

641

642

643

644

645

646

647

648

649

650

651

652

653

654

655

656

China through a drug-target interaction deep learning model. bioRxiv, 10.1101/2020.01.31.929547.

48. Harrison,C. (2020) Coronavirus puts drug repurposing on the fast track. Nat. Biotechnol., 10.1038/d41587-020-00003-1.

49. Shirato,K., Kawase,M. and Matsuyama,S. (2013) Middle East Respiratory Syndrome Coronavirus Infection Mediated by the Transmembrane Serine Protease TMPRSS2. J. Virol., 87, 12552-12561.

50. Chu,C.M., Cheng,V.C.C., Hung,I.F.N., Wong,M.M.L., Chan,K.H., Chan,K.S., Kao,R.Y.T., Poon,L.L.M., Wong,C.L.P., Guan,Y., et al. (2004) Role of lopinavir/ritonavir in the treatment of SARS: Initial virological and clinical findings. Thorax, 59, 252-256.

51. Kaplan,S.S. and Hicks,C.B. (2005) Lopinavir/ritonavir in the treatment of human immunodeficiency virus infection. Expert Opin. Pharmacother., 6, 1573-1585.

52. Razonable,R.R. (2011) Antiviral drugs for viruses other than human immunodeficiency virus. In Mayo Clinic Proceedings. Elsevier Ltd, Vol. 86, pp. 1009-1026.

53. Kupferschmidt,K. (2020) WHO launches global megatrial of the four most promising coronavirus treatments. Science (80-. )., 10.1126/science.abb8497.

54. Gautam,A., Chaudhary,K., Kumar,R. and Raghava,G.P.S. (2015) Computer-aided virtual screening and designing of cell-penetrating peptides. In Cell-Penetrating Peptides: Methods and Protocols. Springer New York, Vol. 1324, pp. 59-69.

55. Ramaiah,A. and Arumugaswami,V. (2020) Insights into Cross-species Evolution of Novel Human Coronavirus 2019-nCoV and Defining Immune Determinants for Vaccine Development. bioRxiv, 10.1101/2020.01.29.925867.

56. Ahmed,S.F., Quadeer,A.A. and McKay,M.R. (2020) Preliminary identification of 

potential vaccine targets for the COVID-19 Coronavirus (SARS-CoV-2) Based on SARS-CoV Immunological Studies. Viruses, 12.

57. Prachar,M., Justesen,S., Steen-Jensen,D.B., Thorgrimsen,S.P., Jurgons,E., Winther,O. and Bagger,F.O. (2020) COVID-19 Vaccine Candidates: Prediction and Validation of 174 SARS-CoV-2 Epitopes. bioRxiv, 10.1101/2020.03.20.000794.

58. Feng,Y., Qiu,M., Zou,S., Li,Y., Luo,K., Chen,R., Sun,Y., Wang,K., Zhuang,X., Zhang,S., et al. (2020) Multi-epitope vaccine design using an immunoinformatics approach for 2019 novel coronavirus in China (SARS-CoV-2). bioRxiv, 10.1101/2020.03.03.962332.

59. Jain,N., Shankar,U., Majee,P. and Kumar,A. (2020) Scrutinizing the SARS-CoV-2 protein information for the designing an effective vaccine encompassing both the T-cell and B-cell epitopes. bioRxiv, 10.1101/2020.03.26.009209.

60. Qamar,M.T. ul, Rehman,A., Ashfaq,U.A., Awan,M.Q., Fatima,I., Shahid,F. and Chen,L.L. (2020) Designing of a next generation multiepitope based vaccine (MEV) against SARS-COV-2: Immunoinformatics and in silico approaches. bioRxiv, 10.1101/2020.02.28.970343.

61. Rahman,M.S., Hoque,M.N., Islam,M.R., Akter,S., Rubayet-Ul-Alam,A.S.M., Siddique,M.A., Saha,O., Rahaman,M.M., Sultana,M. and Hossain,M.A. (2020) Epitopebased chimeric peptide vaccine design against $\mathrm{S}, \mathrm{M}$ and $\mathrm{E}$ proteins of SARS-CoV-2 etiologic agent of global pandemic COVID-19: an in silico approach. bioRxiv, 10.1101/2020.03.30.015164.

62. Behbahani,M. (2020) In silico Design of novel Multi-epitope recombinant Vaccine based on Coronavirus surface glycoprotein. bioRxiv, 10.1101/2020.03.10.985499.

63. Zhou,Y., Hou,Y., Shen,J., Huang,Y., Martin,W. and Cheng,F. (2020) Network-based drug repurposing for novel coronavirus 2019-nCoV/SARS-CoV-2. Cell Discov., 6, 14. 
683

684

685

686

687

688

689

690

691

692

693

694

695

696

697

698

699

700

701

702

703

704

65. Elfiky,A.A. (2020) Ribavirin, Remdesivir, Sofosbuvir, Galidesivir, and Tenofovir against SARS-CoV-2 RNA dependent RNA polymerase (RdRp): A molecular docking study. Life Sci., 10.1016/j.lfs.2020.117592.

66. Wang,M., Cao,R., Zhang,L., Yang,X., Liu,J., Xu,M., Shi,Z., Hu,Z., Zhong,W. and Xiao,G. (2020) Remdesivir and chloroquine effectively inhibit the recently emerged novel coronavirus (2019-nCoV) in vitro. Cell Res., 30, 269-271.

67. Chu,C.M., Cheng,V.C.C., Hung,I.F.N., Wong,M.M.L., Chan,K.H., Chan,K.S., Kao,R.Y.T., Poon,L.L.M., Wong,C.L.P., Guan,Y., et al. (2004) Role of lopinavir/ritonavir in the treatment of SARS: initial virological and clinical findings. Thorax, 59, 252-6.

68. Kong,R., Yang,G., Xue,R., Liu,M., Wang,F., Hu,J., Guo,X. and Chang,S. (2020) COVID-19 Docking Server: An interactive server for docking small molecules, peptides and antibodies against potential targets of COVID-19.

69. Luan,R.-S., Wang,X., Sun,X., Chen,X.-S., Zhou,T., Liu,Q.-H., Lü,X., Wu,X.-P., Gu,D.Q., Tang,M.-S., et al. (2020) [Epidemiology, Treatment, and Epidemic Prevention and Control of the Coronavirus Disease 2019: a Review]. Sichuan Da Xue Xue Bao. Yi Xue Ban, 51, 131-138.

70. Wang,C., Li,W., Drabek,D., Okba,N.M.A., Haperen,R. van, Osterhaus,A.D.M.E., Kuppeveld,F.J.M. van, Haagmans,B.L., Grosveld,F. and Bosch,B.-J. (2020) A human monoclonal 1 antibody blocking SARS-CoV-2 infection. bioRxiv, 10.1101/2020.03.11.987958. 


\section{A web-based platform on COVID-19 to maintain Predicted} Diagnostic, Drug and Vaccine candidates

711 Sumeet Patiyal ${ }^{1 *}$, Dilraj Kaur ${ }^{1 *}$, Harpreet Kaur ${ }^{2 *}$, Neelam Sharma ${ }^{1 *}$, Anjali Dhall ${ }^{1}$, Sukriti

712 Sahai $^{3}$, Piyush Agrawal ${ }^{1}$, Lubna Maryam ${ }^{1}$, Chakit Arora ${ }^{1}$, and Gajendra P.S. Raghava ${ }^{1 \#}$

1. Department of Computational Biology, Indraprastha Institute of Information Technology, New Delhi-110020, India.

2. Bioinformatics Centre, CSIR-Institute of Microbial Technology, Sector 39-A, Chandigarh-160036, India.

3. School of Biotechnology, Gautam Buddha University, Greater Noida, India

* Joint first author

\section{\# Correspondence}

Professor, Department of Computational Biology

Indraprastha Institute of Information Technology,

724 Okhla Industrial Estate, Phase III, New Delhi 110020,

725 India. Tel.: +91011 26907444;

726 E-mail address: raghava@iiitd.ac.in 
731 Table S1: List of 53 Genome sequences that are maintained in CoronaVIR that are used for

732 designing the "Universal" primers for the diagnosis of COVID-19 (SARS-CoV-2).

\begin{tabular}{|c|c|c|c|}
\hline Accession ID & Source country & $\begin{array}{l}\text { Length (No of } \\
\text { nucleotides) }\end{array}$ & Strain \\
\hline MT012098 & India & 29854 & SARS-CoV-2/29/human/2020/IND \\
\hline MT050493 & India & 29851 & SARS-CoV-2/166/human/2020/IND \\
\hline MT152824 & USA & 29878 & SARS-CoV-2/WA2/human/2020/USA \\
\hline MT135042 & China & 29903 & SARS-CoV-2/231/human/2020/CHN \\
\hline MT135041 & China & 29903 & SARS-CoV-2/105/human/2020/CHN \\
\hline MT135043 & China & 29903 & SARS-CoV-2/233/human/2020/CHN \\
\hline MT135044 & China & 29903 & SARS-CoV-2/235/human/2020/CHN \\
\hline MT126808 & Brazil & 29876 & SARS-CoV-2/SP02/human/2020/BRA \\
\hline MT123290 & China & 29891 & SARS-CoV-2/IQTC01/human/2020/CHN \\
\hline MT123291 & China & 29882 & SARS-CoV-2/IQTC02/human/2020/CHN \\
\hline MT118835 & USA & 29882 & 2019-nCoV/USA-CA9/2020 \\
\hline MT106054 & USA & 29882 & 2019-nCoV/USA-TX1/2020 \\
\hline MT106052 & USA & 29882 & 2019-nCoV/USA-CA7/2020 \\
\hline MT106053 & USA & 29882 & 2019-nCoV/USA-CA8/2020 \\
\hline MT093631 & China & 29886 & SARS-CoV-2/WH-09/human/2020/CHN \\
\hline MT093571 & Sweden & 29886 & SARS-CoV-2/01/human/2020/SWE \\
\hline MT072688 & Nepal & 29811 & SARS0CoV-2/61-TW/human/2020/ NPL \\
\hline MT066175 & Taiwan & 29870 & SARS-CoV-2/NTU01/2020/TWN \\
\hline MT066176 & Taiwan & 29870 & SARS-CoV-2/NTU02/2020/TWN \\
\hline MT049951 & China & 29903 & SARS-CoV-2/Yunnan-01/human/2020/CHN \\
\hline MT044258 & USA & 29858 & 2019-nCoV/USA-CA6/2020 \\
\hline MT044257 & USA & 29882 & 2019-nCoV/USA-IL2/2020 \\
\hline MT039890 & South Korea & 29903 & SNU01 \\
\hline MT039887 & USA & 29879 & 2019-nCoV/USA-WI1/2020 \\
\hline MT039873 & China & 29833 & HZ-1 \\
\hline MT039888 & USA & 29882 & 2019-nCoV/USA-MA1/2020 \\
\hline MT027063 & USA & 29882 & 2019-nCoV/USA-CA4/2020 \\
\hline MT027064 & USA & 29882 & 2019-nCoV/USA-CA5/2020 \\
\hline MT027062 & USA & 29882 & 2019-nCoV/USA-CA3/2020 \\
\hline MT019529 & China & 29899 & BetaCoV/Wuhan/IPBCAMS-WH-01/2019 \\
\hline MT019531 & China & 29899 & BetaCoV/Wuhan/IPBCAMS-WH-03/2019 \\
\hline MT019533 & China & 29883 & BetaCoV/Wuhan/IPBCAMS-WH-05/2020 \\
\hline MT020881 & USA & 29882 & 2019-nCoV/USA-WA1-F6/2020 \\
\hline
\end{tabular}




\begin{tabular}{|l|l|l|l|}
\hline MT019532 & China & 29890 & BetaCoV/Wuhan/IPBCAMS-WH-04/2019 \\
\hline MT020880 & USA & 29882 & 2019-nCoV/USA-WA1-A12/2020 \\
\hline MT019530 & China & 29889 & BetaCoV/Wuhan/IPBCAMS-WH-02/2019 \\
\hline MT007544 & Australia & 29893 & Australia/VIC01/2020 \\
\hline MN996528 & China & 29891 & WIV04 \\
\hline MN996530 & China & 29854 & WIV06 \\
\hline MN996527 & China & 29825 & WIV02 \\
\hline MN996531 & China & 29857 & WIV07 \\
\hline MN996529 & China & 29852 & WIV05 \\
\hline MN988669 & China & 29881 & 2019-nCoV WHU02 \\
\hline MN994468 & USA & 29883 & 2019-nCoV/USA-CA2/2020 \\
\hline MN988668 & China & 29881 & 2019-nCoV WHU01 \\
\hline MN997409 & USA & 29882 & 2019-nCoV/USA-AZ1/2020 \\
\hline MN994467 & USA & 29882 & 2019-nCoV/USA-CA1/2020 \\
\hline MN988713 & USA & 29882 & 2019-nCoV/USA-IL1/2020 \\
\hline MN938384 & China & 29838 & 2019-nCoV_HKU-SZ-002a_2020 \\
\hline MN975262 & China & 29838 & 2019-nCoV_HKU-SZ-005b_2020 \\
\hline MN985325 & USA & 29882 & 2019-nCoV/USA-WA1/2020 \\
\hline MN908947 & China & 29903 & Wuhan-Hu-1 \\
\hline NC_045512 & China & 29903 & Wuhan seafoodWuhan-Hu-1 \\
\hline
\end{tabular}

733

736 Table S2: No of the nucleotide-based vaccine adjuvants and siRNA-based vaccine 737 candidates for each of available proteins of SARS-COV-2 (Accession ID MN908947) 738 designed using "VaccineDA" and "desiRM" for vaccine adjuvants and siRNA, 739 respectively.

\begin{tabular}{|l|r|r|}
\hline Protein name & $\begin{array}{l}\text { No of Vaccine } \\
\text { Adjuvants }\end{array}$ & $\begin{array}{l}\text { No of siRNA } \\
\text { candidates }\end{array}$ \\
\hline Envelope protein & 200 & 25 \\
\hline Membrane glycoprotein & 642 & 45 \\
\hline Nucleocapsid protein & 1230 & 35 \\
\hline Orf3a & 800 & 75 \\
\hline Orf1ab & 5251 & 2162 \\
\hline Orf6 & 156 & 168 \\
\hline
\end{tabular}




\begin{tabular}{|l|r|r|}
\hline Orf10 & 89 & 3 \\
\hline Surface protein & 3794 & 699 \\
\hline Orf7a & 340 & 2 \\
\hline Orf8 & 338 & 12 \\
\hline
\end{tabular}

740 